\section{Vol. 71, No. 1}

In the report "Alcohol Consumption and Binge Drinking During Pregnancy Among Adults Aged 18-49 Years — United States, 2018-2020," in the figure on page 12, for Region 8, the values listed should have been $10.8 \%(7.3 \%-14.3 \%)$.

\section{Vol. 71, No. 2}

In the report "Trends in Breast Cancer Incidence, by Race, Ethnicity, and Age Among Women Aged $\geq 20$ Years — United States, 1999-2018," on page 47, in the Summary box, the second sentence in the "What is added by this report?" section should have read, "Incidence increased among non-Hispanic Asian or Pacific Islander women and women aged 20-39 years but decreased among non-Hispanic White women and women aged 50-64 and $\geq 75$ years." 